\title{
SOURCES AND LOSSES OF RING CURRENT IONS: AN UPDATE
}

\author{
J. U. Kozyra \\ Space Physics Research Laboratory, Department of Atmospheric, Oceanic and \\ Space Sciences, The University of Michigan, Ann Arbor, MI 48109-2143, U.S.A.
}

\section{INTRODUCTION}

Major progress has been made in the last three and a half years,in our understanding of the role of ionospheric plasma as a source for the plasma sheet and ring current. Observations by the Dynamics Explorer 1 satellite over the polar ionosphere and concurrent modelling efforts have traced the path of heated ionospheric ions from a localized source associated with the polar cusp along trajectories that energize the ions and deposit them in the near-earth plasma sheet. AMPTE ion composition measurements in the ring current have begun to clarify the relative contributions of the ionospheric and solar wind ions in the plasma sheet and ring current and characterize differences in the energization processes which each population undergoes. The role of charge exchange as a major loss process for the ring current has been confimed by all sky observations onboard the ISEE 1 satellite of energetic neutral atoms resulting from this interaction and associated modeling efforts. The oxygen ion component of the ring current has been found to be a source of heating via Coulomb collisions for the thermal plasmas in the outer plasmasphere with associated loss of energy from the ring current. The role of wave-particle interactions in ring current decay, however, is still unclear.

In the present paper no attempt is made to comprehensively review the large body of literature describing our accumulated knowledge of ring current ion sources and losses. A number of excellent reviews have appeared in the last few years discussing the development of the ring current and its dynamics $/ 1,2,3,4 /$ The present review will concentrate on new developments in our understanding of sources and losses of ring current ions that have taken place during the period 1985 - 1988, overiapping slighty some of the latter reviews cited above with reference to earlier studies as required. The populations comprising the earth's ring current are determined by the strength and composition of ion sources, transport processes, and loss mechanisms. The intent of this review is to focus on processes which supply ions to the ring current and plasma sheet and the decay of the ring current. The transport of ions from the plasma sheet earthward and the subsequent formation of the ring current will not be discussed.

\section{RING CURRENT SOURCES}

\section{Ionospheric Sources of Plasma Sheet Ions}

It is generally considered that the ring current formation is a two-step process (cf. Williams $/ 4,5 /$ and references therein). A series of injection events move plasma inward from the plasma sheet to the outer radiation belts $\left(\geq 5 R_{E}\right)$. In response to enhanced storm-time, dawn-dusk electric fields, this outer trapped population is convected inward $\left(-2.5-5 R_{E}\right)$ to form the ring current. Therefore processes which populate either the plasma sheet or these near earth regions with plasma are considered, for the purposes of this review, sources of the ring current plasma. Plasma in these regions is likely a mixture of solar wind and ionospheric populations.

Observations from the Dynamics Explorer 1 satellite of upflowing ionospheric ions ( $\mathrm{H}^{+}, \mathrm{He}, \mathrm{O}^{+}, \mathrm{N}^{+}$, and $\mathrm{O}^{++}$), along with theoretical models investigating the transport of these ions into the polar magnetosphere, have established the dayside cusp region as a copious and persistent source of upflowing heated ionospheric plasma $7,8,9,10,11,12,13,14,15,16,17,18,19 /$. The characteristics of this ionospheric source are listed below so that these may later be compared with measurements of the ion composition of the plasma sheet and ring current and the changes in this composition with solar cycle and magnetic activity.

These ion upflows have been labelled 'upwelling ion events' because all ion species participating in the event display the effects of equal ion heating to parallel and perpendicular temperatures of about 2 and $10 \mathrm{ev}$, respectively $19 \%$. Upwelling ion events have been statistically correlated with field aligned currents /4/. For one particular event studied in detail, the ionospheric heating was coincident with magnetic field signatures of strong field-aligned curnents on the boundary of the dayside polar cap /13/. Also present on these field lines was a strong, localized convection channel or jet. Observations and theoretical models point out the importance of ion heating (which aids the heavy ions in overcoming the gravitational barrier) in producing heavy ion outflows in the polar magnetosphere. Studies of transient polar wind oufflow in the presence of low altitude ion heating $/ 20 /$ indicate that significant heavy ion outflows will result $120 \%$. Lockwood et al. $/ 21$ / have pointed out that ion outflows from this region could be enhanced by the ionospheric effects of flux transfer events (FTE) on the dayside magnetopause which map to the polar cap boundary. The roughly equal heating of the various ion species implies that field aligned flow velocities will be inversely proportional to the square root of the ion mass. This mass dependent velocity, in combination with the ExB convection and the localized nature of the upwelling ion source, results in a dispersion of these ions by mass and velocity as they convect across the polar cap /12/. This effect has been termed the "geomagnetic mass spectrometer" and results in the lowest-energy and highest 
mass ions extending turthest toward the nightside trom the clett ionosphere. This upwelling ion source region has also been termed the cleft ion fountain $/ 22 /$ because as convection becomes antisunward and strong, ions are dispersed further onto the nightside, analogous to a fountain blowing in the wind. $\mathrm{O}^{+}$outflows increase both with increasing solar radio flux at $10.7 \mathrm{~cm}$ $\left(F_{10.7}\right)$ and with increasing magnetic activity: $\mathrm{H}^{+}$outflows exhibit no marked variation with solar cycle and a much smaller variation with magnetic activity than that shown by the $0^{+}$outflows $/ 23 /$. Figure 1 is a schematic illustration of the ion ouflows from the polar cleft and polar cap regions taken from Horwitz /24/.

The question of how these ionospheric oufflows from the cleft ion fountain reach the plasma sheet was addressed by Cladis $/ 25 /$ using a kinetic. guiding-center trajectory-based code with ion motion computed only near the noon-midnight meridional plane. The ions are accelerated along trajectories due to the centrifugal force arising from the ion convection velocity and the energy supplied by the component of the curvature drift of the ion along the convection electric field. Figure 2a displays ion guiding center trajectories projected on the noon-midnight plane from Cladis $/ 25 /$ for four different conditions of the magnetic and electric field. $\mathrm{O}^{+}$ions can reach the center plane of the plasma sheet even at times of moderate convection. Total energy of $\mathrm{O}^{+}$ions along these trajectories are shown in Figure $2 b$ as a function of time. During magnetically disturbed conditions the $\mathrm{O}^{+}$trajectories intersect the center plane of the magnetosphere more earthward than during quiet times. The $\mathrm{O}^{+}$ions can be energized to typical plasma sheet energies along these trajectories with travel times between the ionosphere and the center plane of 1-2 hours. Figure $3 \mathrm{a}$ from Cladis $/ 25$ / illustrates the dependence of the ion motion on its initial location in the polar ionosphere and Figure $3 \mathrm{~b}$ demonstrates this dependence on initial ion velocity. Ions gain higher energies and cross the center plane at larger radial distances as their initial positions approach the cusp field lines. A similar trend results from increasing the ion parallel velocities. The net result is an increase in heavy ion content of the plasma sheet with decreasing radial distance. The combination of the satellite observations detailed above and the trajectory calculations of Cladis 25 / indicates a large proportion of the ionospheric ions observed in the plasma sheet during magnetically disturbed periods originate in the cleft ion fountain. In addition Cladis $25 /$ has shown that these ions reach appropriate energies prior to injection in the plasma sheet and require no additional energization. The origin of the $\mathrm{H}^{+}$injected from this source region, however, is still ambiguous, since the $\mathrm{H}^{+}$population in the dayside cusp region at the energies and altitudes of interest, is likely a mixture of solar wind and ionospheric ions. On appropriate trajectories. Lockwood et al. $/ 7$ have suggested that heavy ion outflows will act as a source for the nightside auroral acceleration region. Figure 4 illustrates schematically how this might occur.

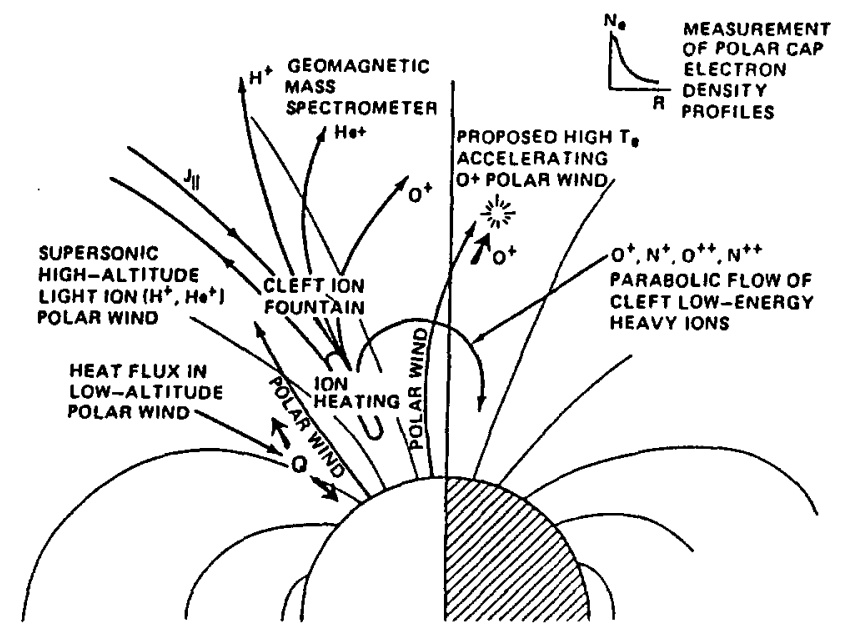

Fig. 1. Schematic illustration of ion outflows in the polar ionosphere taken from $/ 24 /$.
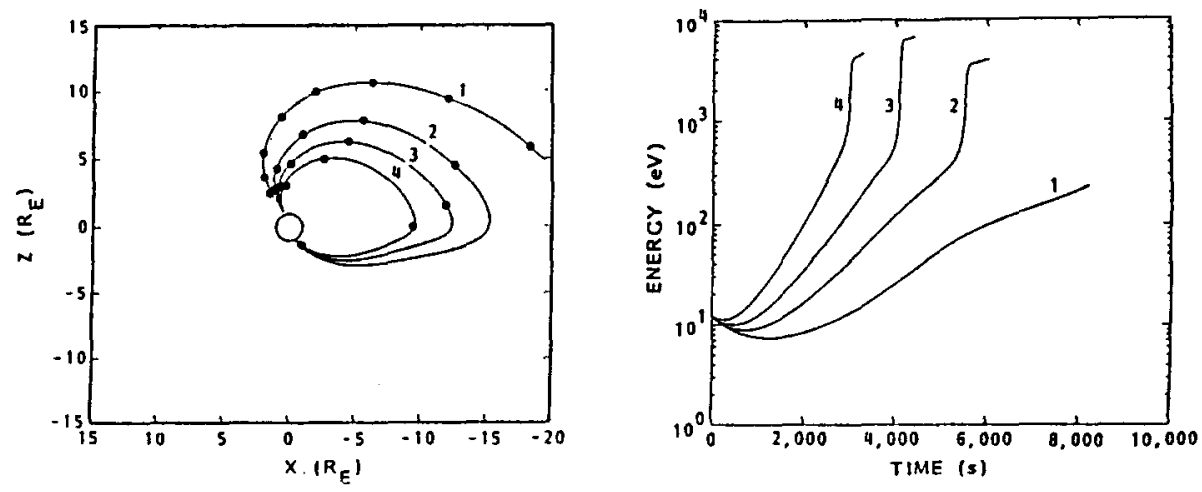

Fig. 2. (a) Guiding-center trajectories projected on the $X-Z$ plane of ions flowing out of the polar cleft region during different levels of magnetic disturbance. In the simulation, the ions were started at $1.2 \mathrm{RE}, \theta=22^{\circ}, \phi=0^{\circ}$ with $\mathrm{V}=12 \mathrm{~km} / \mathrm{s}$ and $\alpha=$ $30^{\circ}$. Disurbed conditions in curves $1-4$, respectively, are represented by parameters $\left(E_{i}, K_{p}\right)$ of $(23.3 \mathrm{mV} / \mathrm{m}, 2-),(40 \mathrm{mV} / \mathrm{m}$, $2+),(56.7 \mathrm{mV} / \mathrm{m}, 3-$ to $3+)$, and $(80 \mathrm{mV} / \mathrm{m},>3+)$. Arrival times in steps of 1000 seconds are denoted by dots along each trajectory. This figure was taken from 25 i)

(b) Energy achieved by the $\mathrm{O}^{+}$ions as they travel along trajectories $1-4$ shown in panel a $25 /$. 

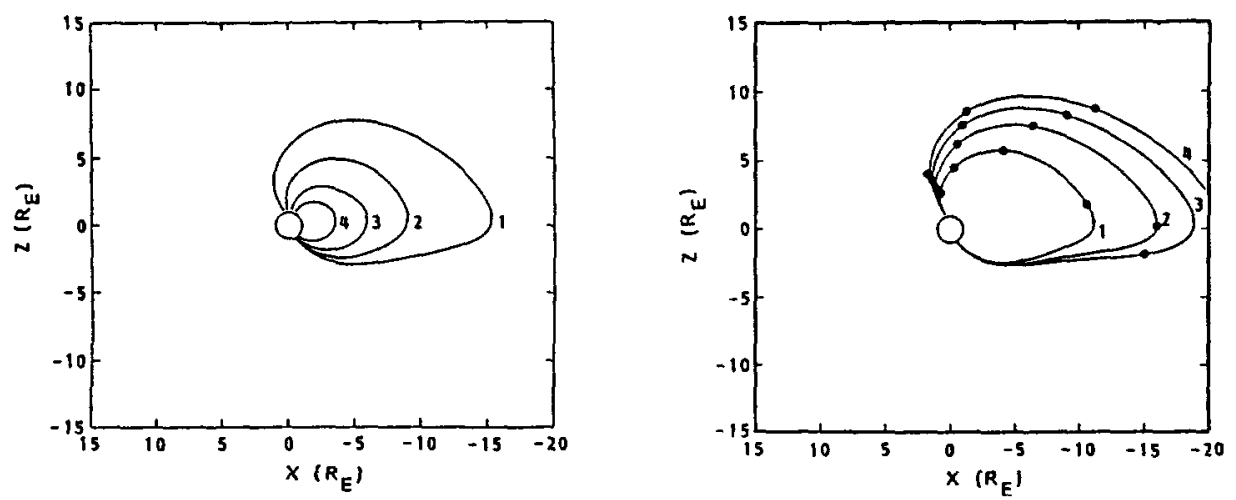

Fig. 3. (a) Guiding-center trajectories of ions flowing out of the ionosphere from different locations across the polar cap. All of the ions were started with initial velocity of $12 \mathrm{~km} / \mathrm{s}$ and initial pitch angle of $30^{\circ}$ under the influence of a polar cap potential of $E_{i}=40 \mathrm{mV} / \mathrm{m}$ and $K_{p}=2+$. (from $/ 25 /$ ).

(b) Guiding-center trajectories of ions flowing out of the polar cleft region with different initial velocities. Curves $1-4$ correspond to ions with initial velocities of $10.95,14.70,17.66$, and $20.20 \mathrm{~km} / \mathrm{s}$, respectively and pitch angles of $0^{\circ}$. The cross polar cap potential was held constant at $E_{i}=56.7 \mathrm{mV} / \mathrm{m}$, and $\mathrm{K}_{\mathrm{p}}$ at $3-$ to $3+$. Arrival times in steps of 1000 seconds are denoted by dots along each trajectory. (from $/ 25 /$ ).

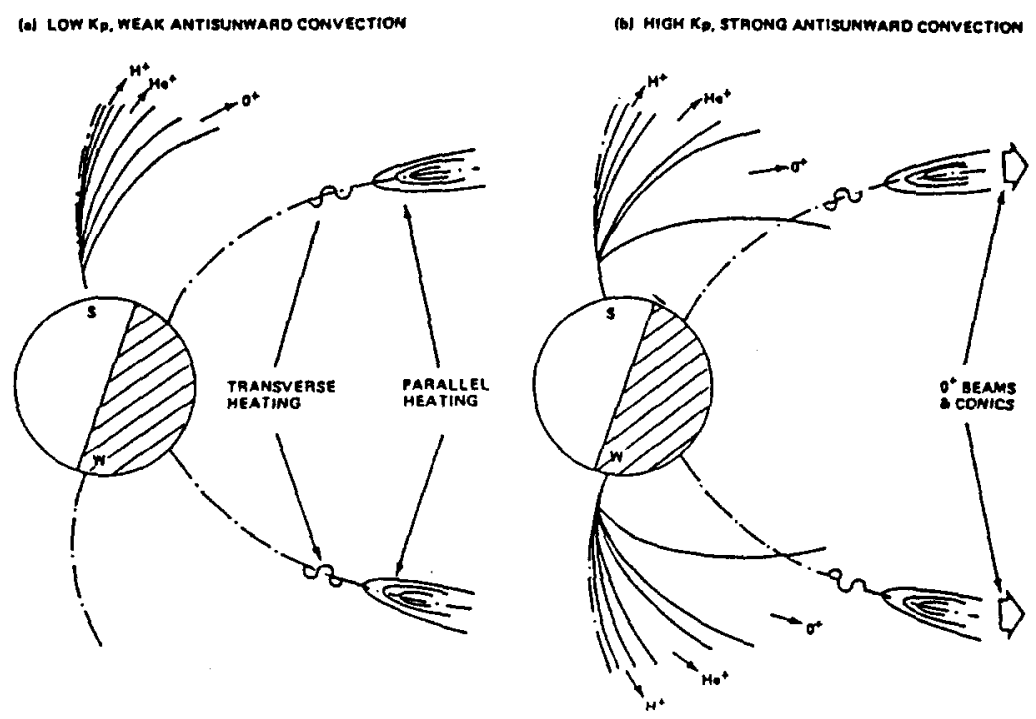

Fig. 4. Schematic diagram of low-energy ion outflows from the Cleft Ion Fountain during solstice conditions. Solid lines represent ion trajectories, dashed lines represent auroral field lines, $\mathrm{S}$ denotes the auroral oval in the summer hemisphere and $\mathrm{W}$ that in the winter hemisphere. For conditions of weak, anti-sunward, convection depicted in (a), upflowing ions from this region act as a source of heavy ions (particularly $\mathrm{O}^{+}$) for the polar cap. During strong, anti-sunward, convection illustrated in (b), ion oufflows from the cleft region may act as a source of heavy ions for the auroral acceleration region. (from $\pi /$ ).

\section{Ionospheric Source - Direct Iniection into the Ring Current}

Evidence for the direct injection of ionospheric ions into the ring current has been accumulating for many years (cf., Horwitz 26 ; Williams $/ 27$ /; Young $/ 28 /$ ). In a survey of two years (November 1981 to December 1983) of observations by the AUREOL 3 spacecraft, the characteristics of downward flowing ion (DFI) beams have been recently investigated $/ 29 \% \mathrm{H}^{+}$ions are always dominant in these flows. This is very interesting since upward flowing ion (UFI) beams have compositions which range from pure $\mathrm{H}^{+}$to pure $\mathrm{O}^{+} 30,31$ and are much more frequently observed $32 \%$. Bosqued et al. $/ 29 /$ interpret these results to mean that UFI beams are scattered in pitch angle near the equatorial plane. Kaye et al. B3/ had previously suggested this as a mechanism for direct injection of kev ions into the ring current. $\mathrm{O}^{+}$ions have longer bounce times than $\mathrm{H}^{+}$ions of comparable energy. The effects of scattening and transport will be larger for longer bounce times. Therefore, UFI beams containing $\mathrm{O}^{+}$will be scattered in pitch angle more than their $\mathrm{H}^{+}$counterparts and will be less likely to reach the conjugate hemisphere and be observed as DFI beams.

Upflowing ion beams and conics generally occur at $L$ shells poleward of the plasmasphere. Direct injection of upflowing $(<100$ $\mathrm{eV}$ ions, predominantly $\mathrm{O}^{+}$, inside or at the plasmapause, have now been observed during a number of magnetic storms in the midnight and early moming sectors during the main phase of magnetic storms $134,35 /$ and in the dayside during the recovery phase $136 /$. Ions at energies less than $1 \mathrm{KeV}$ participate in corotation and thus cannot be strictly considered as ring current ions but these ions are a part of the energetic ion environment in the outer plasmasphere. For completeness, they are included in this discussion. 
Newell and Meng /37/ report on observations by the DMSP satellite of up to $1 \mathrm{KeV}$ ion precipitation within the plasmasphere as a common fearure during and after prolonged magnetic substom activity. They infer that injections occur from postmidnight to 8:30 MLT and the ions subsequently co-rotate and precipitate with a lifetime of approximately 1 day. There is indirect evidence that these ions are predominandy $\mathrm{O}^{+}$. Though Newell and Ming site magnetospheric injection processes as a potential source, these observations are remarkably similar to those of Bosqued $/ 34 /$, Jorjio $/ 35 /$, and Menieti et al. $/ 36 /$ which indicate an ionospheric source.

\section{Plasmaspheric Source - Direct Iniection}

Theoretical studies $38,39,40,41$ and references therein/ and observations (Korth et al. /42/. Inhestor et al.J43/, and Fraser et al. 144/) indicate that plasmaspheric $\mathrm{He}^{+}$and $\mathrm{O}^{+}$ions can gyroresonate with ion cyclotron waves in the dusk bulge region, and increase their energy and pitch angle. After this local energization, the ions essentially become part of the ring current populations. Figure $5 / 45 /$ shows the relationship between the observation of ion cyclotron waves and the appearance of energetic $\mathrm{He}^{+}$ions in the inner magnetosphere.

\section{Estimated Strength of the Ionospheric Source}

Prompted by the discovery of a new and very significant source of upflowing ionospheric plasma from the cleft ion fountain described above, in addition to other previously identified sources of upflowing plasma in the auroral zone $/ 46,23 \%$. Chappell et al. $/ 47 /$ have attempted to estimate the ionospheric contribution to magnetospheric ion populations throughout the terrestrial magnetosphere. Using recent data on the ionospheric source strength, along with estimated volumes and ion residence times for each magnetospheric region (plasmasphere, plasma trough, plasma sheet and magnetotail lobes), the authors demonstrated that the ionosphere was likely a dominant source of magnetospheric plasma during quiet and active magnetic conditions in all of these regions. Of interest for the present review is their estimation of the importance of the ionspheric source for plasma sheet ions. Sources of ionospheric plasma for the plasma sheet were considered to be : (1) upflowing ions from the auroral zone through direct entry into the plasma sheet boundary layer (2) the polar wind $\left(\mathrm{H}^{+}\right.$and $\left.\mathrm{He}^{+}\right)$, (3) the cleft ion fountain and (4) the polar cap ionosphere. Because of the flow trajectories of the ions from each of these source regions, the cleft ion fountain source is more significant in the first 10-20 RE of the plasma sheet, whereas the auroral source is more important tailward. Composition will also vary as a result of these trajectories. $\mathrm{O}^{+}$fluxes from the cleft ion fountain intersect the plasma sheet near 7-15 RE: whereas, $\mathrm{H}^{+}$fluxes from this same region will contribute to the plasma sheet at distances of 15-50 RE. Figure 6 from Chappel et al. /47/ is a schematic diagram of the magnetosphere showing the plasma sheet during quiet and active magnetic conditions; and displaying sample ion trajectories from each of the major ionospheric source regions.

Table 1 summarizes the flux contributions to the plasma sheet during sol ar maximum and solar minimum from each of the ionospheric sources. The largest outflows of $\mathrm{H}^{+}$and $\mathrm{He}^{+}$occur from the polar wind source during quiet magnetic conditions at solar minimum. In contrast, the largest $\mathrm{O}^{+}$outflows occur during active conditions at solar maximum. Calculated plasma sheet densities due solely to an ionospheric source were $0.73-0.42 \mathrm{~cm}-3$ for quiet conditions and $6.3-6.0 \mathrm{~cm}-3$ for active magnetic

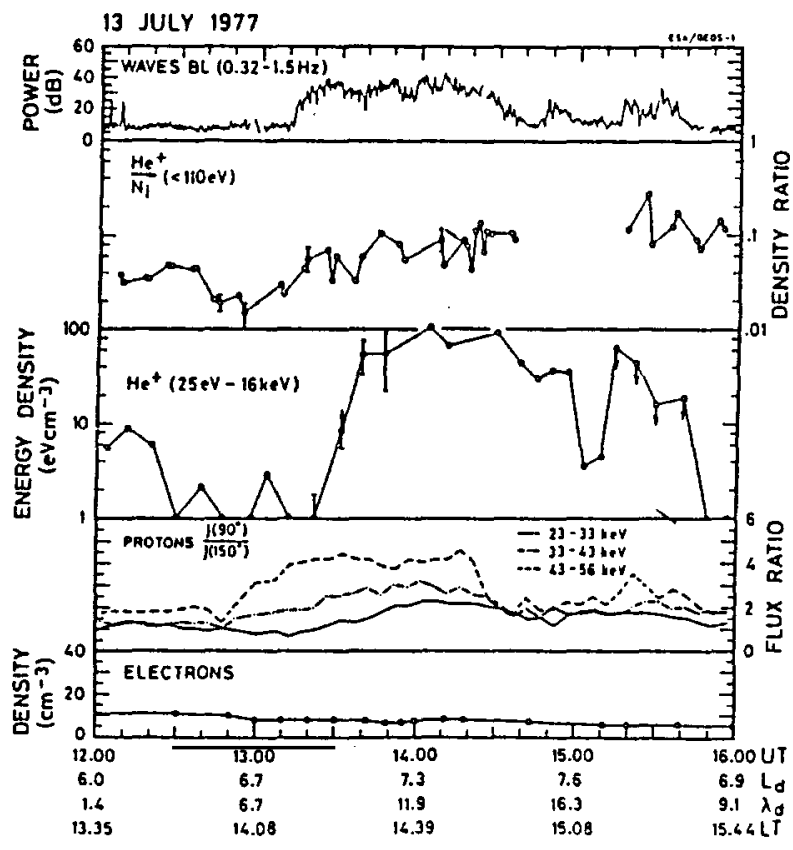

Fig. 5. Simultaneous wave and particle measurements on board GEOS 1 on July 13,1977 indicative of $\mathrm{He}^{+}$heating by waves. The panels, from top to bottom, are (1) wave power in the L-mode relative to $10^{-5} \gamma^{2} / \mathrm{Hz}$, (2) relative abundance of $\mathrm{He}^{+}$in the total ion population below $110 \mathrm{ev},(3) \mathrm{He}^{+}$energy density above $25 \mathrm{ev}$ which increases dramatically after wave onset (indicative of wave heating), (4) energetic proton anisotropy (ratio of $90^{\circ}$ to $150^{\circ}$ fluxes) in the lowest three energy channels, and (5) local cold electron density determined by the wave propagation experiment on GEOS 1. (after/45/). 
conditions. These results demonstrate that the ionosphere is a large source of magnetospheric plasma and. in fact, may be the dominant source in the near-earth plasmasheet.

a

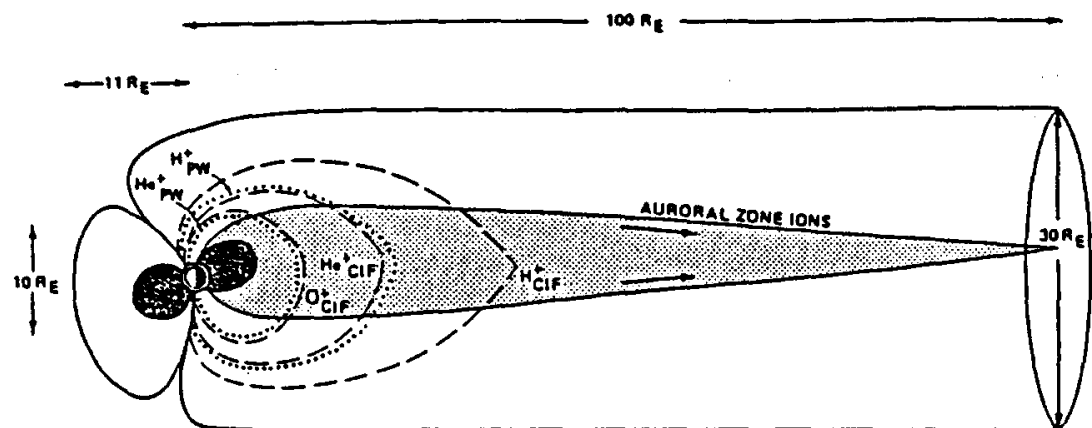

OUIET PLASMA SHEET CONDITIONS

b

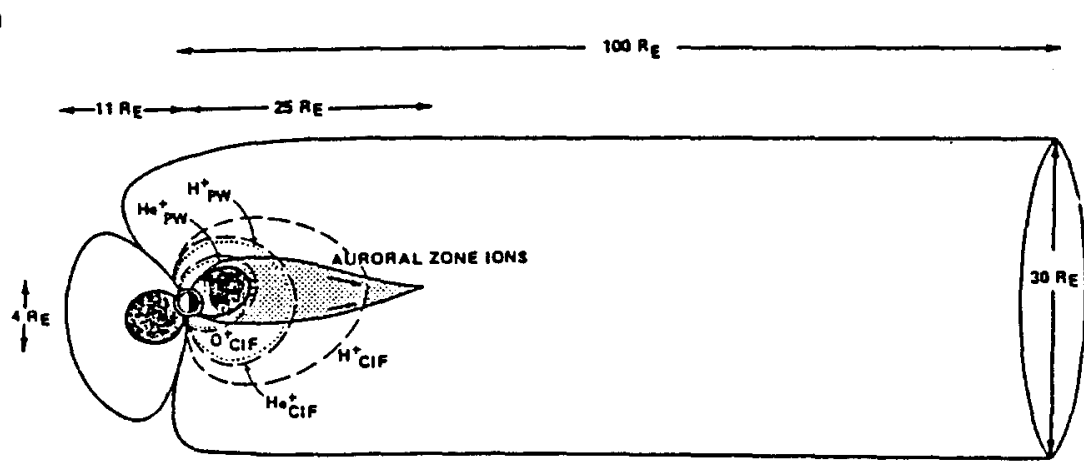

active PLASMA SHEET CONOITIONS

Fig. 6. Schematic diagram of the magnetosphere showing assumed sizes of the plasma sheet for (a) quite and (b) active magnetic conditions and depicting the outer flow boundary for polar wind (dotued line) and cleft ion fountain ions (dashed line). (from $/ 47 /$ ).

TABLE I Detailed Fluxes Into Plasma Sheet

\begin{tabular}{|c|c|c|c|c|c|c|}
\hline & \multicolumn{3}{|c|}{ Solar Maximum } & \multicolumn{3}{|c|}{ Solar Minimum } \\
\hline & $\mathrm{H}^{-}$ & $\mathrm{He}^{+}$ & $\mathrm{O}^{+}$ & $\mathrm{H}^{+}$ & $\mathrm{He}^{*}$ & $0^{+}$ \\
\hline $\begin{array}{l}\text { Quiet plasma sheet } \\
\text { Polar wind } \\
\text { Cleft ion fountain } \\
\text { Auroral zone } \\
\text { Polar cap }\end{array}$ & $\begin{array}{l}4.7 \times 10^{23} \\
3.3 \times 10^{24} \\
2.1 \times 10^{25} \\
2.4 \times 10^{24}\end{array}$ & $3.3 \times 10^{24}$ & $\begin{array}{l}1.6 \times 10^{25} \\
1.6 \times 10^{23} \\
2.4 \times 10^{24}\end{array}$ & $\begin{array}{l}1.4 \times 10^{26} \\
6.3 \times 10^{24} \\
1.7 \times 10^{23} \\
4.3 \times 10^{24}\end{array}$ & $1.8 \times 10^{24}$ & $\begin{array}{l}7.3 \times 10^{24} \\
1.0 \times 10^{25} \\
3.9 \times 10^{24}\end{array}$ \\
\hline Total & $7.4 \times 10^{25}$ & $3.3 \times 10^{24}$ & $3.4 \times 10^{25}$ & $1.7 \times 10^{26}$ & $1.8 \times 10^{24}$ & $2.1 \times 10^{25}$ \\
\hline Total lons & & $1.1 \times 10^{26}$ & & & $1.9 \times 10^{26}$ & \\
\hline $\begin{array}{l}\text { Active plasma sheef } \\
\text { Polar wind } \\
\text { Cleft ion fountain } \\
\text { Auroral zone } \\
\text { Polar cap }\end{array}$ & $\begin{array}{l}3.2 \times 10^{29} \\
4.3 \times 10^{24} \\
2.6 \times 10^{29} \\
6.1 \times 10^{24}\end{array}$ & $1.2 \times 10^{24}$ & $\begin{array}{l}4.8 \times 10^{25} \\
7.7 \times 10^{25} \\
2.5 \times 10^{25}\end{array}$ & $\begin{array}{l}9.4 \times 10^{25} \\
4.3 \times 10^{24} \\
3.3 \times 10^{25} \\
1.0 \times 10^{25}\end{array}$ & $8.6 \times 10^{23}$ & $\begin{array}{l}1.9 \times 10^{25} \\
3.2 \times 10^{25} \\
1.5 \times 10^{25}\end{array}$ \\
\hline Total & $6.7 \times 10^{23}$ & $1.2 \times 10^{24}$ & $1.5 \times 10^{26}$ & $1.4 \times 10^{26}$ & $8.6 \times 10^{23}$ & $6.6 \times 10^{25}$ \\
\hline Total Ions & & $2.2 \times 10^{26}$ & & & $2.1 \times 10^{26}$ & \\
\hline
\end{tabular}

Fluxes given in ions $\mathbf{s}^{-1}$.

After $/ 47 /$. 


\section{Solar Wind Versus lonospheric Source - Ring Current and Plasma Sheet Composition Measurements}

The AMPTE spacecraft, launched in 1984, are capable of making in-situ measurements of ring current and plasma sheet composition in the energy range 0.3-315 keV/e (AMPTE/CCE) and 5-270 keV/e (AMPTE/RM). Initial composition measurements by AMPTE and their implications are summarized in Gloeckler and Hamilton /48/. Key results of relevance to clarifying the ion sources are:
1) $\mathrm{O}^{+}, \mathrm{N}^{+}, \mathrm{He}^{+}, \mathrm{O}^{++}$and $\mathrm{NO}^{+}$and $\mathrm{O}_{2}^{+}$are observed in the storm-time ring current at energies up to $\sim 300 \mathrm{keV} / \mathrm{e}$ on a time scale of a few hours proving the ability of magnetospheric processes to energize ionospheric ions to ring current energies /49/. The time scales for the appearance of energetic heavy ions in the ring current following storm commencement are consistent with transport times for ionospheric ions from the cleft ion fountain to the center plane of the plasma sheet calculated by Cladis $25 \%$.

2) Questions regarding the origin of ring current ions can be addressed by considering observations of oxygen ions with various charge states. Higher charge states of oxygen and carbon $\left(\mathrm{C}_{6}^{+}, \mathrm{O}_{6}^{+}\right)$ in general are found in the solar wind and lower charge states of oxygen $\left(\mathrm{O}^{+}, \mathrm{O}_{2}^{+}\right)$in the ionosphere. An unambiguous determination of the source is not possible due to charge exchange processes $/ 50 /$ which may increase or decrease the charge state of a particular ion. In many cases, however, the dominant source can still be identified. Observations indicate that ionospheric origin ions $\left(\mathrm{O}^{+}, \mathrm{O}_{2}^{+}\right)$fall off with increasing $\mathrm{L}$ while solar wind origin ion $\left(\mathrm{C}_{6}^{+}, \mathrm{O}_{6}{ }^{+}\right)$intensities increase with increasing $L$ (see Figure 7 ) indicating two different sources, one in the near-earth region and the other in the tail $/ 51 /$. This is consistent with the entry of solar wind ions into the magnetosphere and the entry of ionospheric ions through the cleft ion fountain and auroral acceleration regions. The entry of solar wind ions is thought to occur near the dayside cusp and the low latitude flank. These solar wind ions then convect into the tail and move toward the tail plasma sheet. The observations presented in Kremser et al. /51/indicate that the ionosphere is indeed the main source of $\mathrm{O}^{+}$ions in the magnetosphere. Important contributions from the solar wind are encountered in the outer magnetosphere.

3) Gloeckler and Hamilton/48/ estimated the fractions of ionosphere to solar wind ions in the plasma sheet and ring current during quiet and disturbed times taking into account charge exchange losses from higher to lower charge states in each region and approximating solar wind and ionospheric contributions to $\mathrm{H}^{+}$by looking at the amount of solar wind versus ionospheric origin heavy ions in the region. (See Table II after Gloeckler and Hamilton/48/). These results indicate that as much as $40-80 \%$ of the ring current and near earth plasma sheet ion population is ionospheric in origin.

Lennartsson and Shelley $/ 52 /$, with a large data base from ISEE1 of plasma sheet ion composition between 0.1 and $16 \mathrm{keV} / \mathrm{e}$ between 10 and 23 Re during 1978 and 1979 , were able to contribute information on the variation of the heavy ion content of the plasma sheet with magnetic activity and solar cycle. This study built on the results of previous statistical studies of smaller subsets of the ISEE 1 data base $153,54,55 /$. The major findings of relevance to this review are

1. The $\mathrm{O}^{+}$density in the plasma sheet increased by a factor of 3 between early 1978 and early 1979 . possibly in response to increasing solar EUV, indicaring a significant solar cycle variation in the heavy ion content of the plasma sheet.

2. Solar wind origin ions and ionospheric ions populate the plasma sheet under different geomagnetic conditions. ISEE observations clearly show that $\mathrm{O}^{+}$and the ratio of $\mathrm{O}^{+}$to $\mathrm{H}^{+}$ increases with increasing AE on the average but the average energy of the $\mathrm{O}^{+}$ions does not change. On the other hand, ions of solar wind origin are most numerous and least energetic during periods of extreme quiet. $\mathrm{H}^{+}$and $\mathrm{He}^{++}$during quiet times appear to approach energies that are comparable to kinetic energies in the solar wind. This behavior is displayed in Figure 8.

\section{Interpretation of Composition Variations}

Many of the variations in the composition of the ring current plasma statistically observed by high altitude spacecraft (ISEE1, AMPTE) can be explained by the variations of the ionospheric source with solar cycle and magnetic activity 25,47 and others/. lonospheric ions, at low enough energies to be influenced by gravity and magnetospheric convection, are dispersed by mass and energy as they convect across the polar cap $/ 22,15,11,25 /$. This dispersion will affect the observed spatial distribution of plasma sheet ion populations, even in the absence of a solar wind source $/ 47 /$, producing a ratio of $\mathrm{O}^{+} / \mathrm{H}^{+}$in the plasma sheet that increases with decreasing radial distance.

Cladis $/ 25 /$ demonstrated that, even during times of moderate convection, upward flowing $\mathrm{O}^{+}$ions (with velocities exceeding escape velocity) could be transported to the inner plasma sheet (Figure 2a). Observations of the ionospheric outflow of $\mathrm{O}^{+}$ions by the Dynamics Explorer satellite $7,10,22,56 /$ indicate that the $\mathrm{O}^{+}$outflow increases as magnetic activity increases; and Young et al. $157 /$ have demonstrated that the number densities of $\mathrm{He}^{+}, \mathrm{O}^{+}$, and $\mathrm{O}_{2}^{+}$in the plasma sheet and ring current have a strong solar cycle variation increasing with increasing solar radio flux $\left(\mathrm{F}_{10.7}\right)$ upon which is superposed magnetic activity variations. These findings indicate that increased $\mathrm{O}^{+}$density in the plasma sheet during high magnetic activity (shown in Figure 8) is more likely due to an increase in the source of escaping $\mathrm{O}^{+}$rather than to a modification of the transport path $25 \%$. 


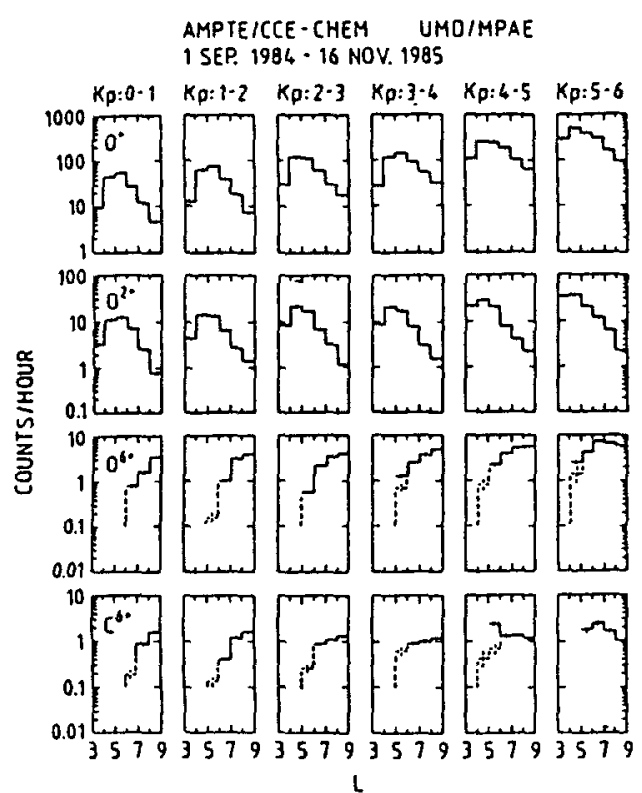

- ALL OATA

- SELECTED DATa ILOW BACKGR.)

Fig. 7. Relative fluxes of $\mathrm{O}^{+}, \mathrm{O}^{2+}, \mathrm{O}^{6+}$, and $\mathrm{C}^{6+}$ versus $\mathrm{L}$ shell for different levels of magnetic activity as indicated by $\mathrm{K}_{\mathrm{p}}$. Solid lines represent all data while dashed lines represent data selected for low background counts. (from $/ 51 /$ ).

Table 2 Estimates of ionospheric origin ion ratios and fractions of ionospheric origin ions in various magnetospheric regions

\begin{tabular}{|c|c|c|c|c|c|}
\hline \multirow[b]{3}{*}{ Ratio } & \multirow[b]{3}{*}{ Condition } & \multicolumn{4}{|l|}{ Region } \\
\hline & & \multicolumn{2}{|l|}{ Plasma sheet } & \multicolumn{2}{|l|}{ Ring current } \\
\hline & & $15 R_{\varepsilon^{*}}$ & $B-9 R_{q}^{*}$ & $S-7 R_{R^{6}}$ & $3-5 R_{\varepsilon^{*}}$ \\
\hline $\mathrm{Hi}_{\mathrm{i}} / \mathrm{O}^{*}$ & $\begin{array}{l}\text { Quiet } \\
\text { Disturbed }\end{array}$ & $\begin{array}{l}11 \pm 1 \\
6 \pm 0.5\end{array}$ & $9 \pm 1$ & $\begin{array}{l}6.5 \pm 1.2 \\
1.3 \pm 0.3\end{array}$ & $\begin{array}{c}11 \pm 0.5 \\
1.3 \pm 0.03\end{array}$ \\
\hline $\mathrm{O}^{*} / \mathrm{He}_{i}^{*}$ & $\begin{array}{l}\text { Quiet } \\
\text { Disturbed }\end{array}$ & $\begin{array}{l}24 \pm 22 \\
20 \pm 1\end{array}$ & $22 \pm 1$ & $\begin{array}{l}16 \pm 4 \\
70 \pm 10\end{array}$ & $\begin{array}{l}27 \pm 3 \\
80 \pm 20\end{array}$ \\
\hline $\mathrm{H}_{\mathrm{i}}^{+} / \mathrm{H}_{\mathrm{i}}^{*}$ & $\begin{array}{l}\text { Quiet } \\
\text { Disturbed }\end{array}$ & $\begin{array}{l}0.36 \pm 0.06 \\
0.62 \pm 0.05\end{array}$ & $0.45 \pm 0.05$ & $\begin{array}{l}0.35 \pm 0.10 \\
0.30 \pm 0.05\end{array}$ & $\begin{array}{l}0.75=0.05 \\
0.67 \pm 0.05\end{array}$ \\
\hline$n_{t} / n_{\text {tom }}$ & $\begin{array}{l}\text { Quiet } \\
\text { Disturbed }\end{array}$ & $\begin{array}{l}0.37 \pm 0.07 \\
0.65 \pm 0.06\end{array}$ & $0.47 \pm 0.06$ & $\begin{array}{l}0.38 \pm 0.11 \\
0.46 \pm 0.07\end{array}$ & $\begin{array}{l}0.76 \pm 0.06 \\
0.75 \pm 0.06\end{array}$ \\
\hline$r_{0} / r_{0}{ }^{4}$ & & 1.76 & & 1.21 & 1.0 \\
\hline
\end{tabular}

: 28-226keV/e.

$\because 1.5-315 \mathrm{keV} / \mathrm{e}$.

- 20-315 keV/e.

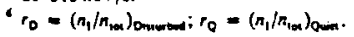

After $/ 48 /$

\section{RING CURRENT LOSS PROCESSES}

\section{Charge-Exchange Decay}

The dominant loss process for the ring current is charge exchange of ring current ions with the hydrogen geocorona although pitch angle diffusion due to wave particle interactions and Coulomb collisional losses are assumed to play a role (cf. Williams $/ 1,3,4,6,27 /$. The role of these secondary processes has not been clearly defined. In the last several years, interesting results have appeared verifying the dominant role of charge exchange and clarifying somewhat the role of wave particle interactions and coulomb collisions with the cold thermal ions of the plasmasphere.

Recently significant progress has been made toward obtaining a global view of ring current development and evolution $/ 58$. Roelof et al. have developed a method for identifying and analyzing energetic neutral atoms (ENA) emanating from the ring current region as a result of charge exchange reactions of ring current ions with the neutral $\mathrm{H}$ geocorona. The modeling process provides additional confirmation of the dominant role charge exchange plays in ring current decay. 
The ISEE1 energetic neutral atom (ENA) emission function cannot be inverted uniquely from a single vantage point to obtain information on the ring current ion distribution. Analysis of the ENA image proceeds by the following method: (1) a simple model of the ring current ion population is constructed. (2) the ENA flux due to charge exchange with the $\mathrm{H}^{+}$geocorona is obcained using this simple model of the ring current ion distributions, (3) the inferred neutral particle flux is convolved with the ISEE1 telescope response function. (4) the simulated instrument response is compared to observations made by the ISEEl spacecraft. (5) this process is iterated until reasonable agreement is achieved. The remarkable agreement in general morphology, obtained by the authors, between these two images, using this procedure with reasonable ring current ion distributions, provides strong support for the dominant role of charge exchange in ring current decay.

\section{Pitch Angle Diffusion}

It is generally agreed that pitch angle diffusion as a result of wave paricle interactions constitutes a minor but important ring current loss mechanism (see reviews $/ 1,3,4,6)$, but the plasma waves causing the observed pitch angle diffusion have not been clearly identified within the plasmasphere. Recent observational evidence from the VIKING spacecraft for the importance of pitch angle diffusion in ring current decay was offered by Studeman et al. 159\%. During the May 2-3. 1986 storm onset, while increased fluxes of tens of kev protons were observed on the eveningside of the inner ring current region, the momingside continued to exhibit the quiet-time inner ring current proton spectra for several hours. Drift periods due to the gradients in the magnetic field for 30 and $100 \mathrm{kev}$ protons on an $L$ shell of 4 were calculated by the authors to be 7.1 and 1.6 hours, respectively compared to charge exchange e-folding decay times of 9.4 and 101 hours, respectively. They conclude that charge exchange was partly responsible for the loss of low-energy ring current protons as they travelled along drift paths prior to reaching the momingside but could not account for losses at high energies. Observations of isotropic proton pitch angle distributions were taken as an indication that strong pitch angle scattering was removing protons from the ring current before these ions were able to reach the morningside.

A search for the waves responsible for the loss of ring current protons via pitch angle diffusion continues. As early as 1970 , Comwall et al. $/ 60 /$ predicted that ion cyclotron waves (ICW's) should be present in the plasmapause region and the resulting

pitch angle diffusion would represent a loss process for the ring current protons. To date, ICW's have not been observed with sufficient regularity or duration within the high-density, plasmasphere to support their importance in ring current decay in this region (see discussion in /61/; although some indirect evidence of their presence exists. The proton precipitation, which presumably results from pitch angle diffusion of ring current ions resonating with these waves, has been observed. A region of moderately anisotropic proton precipitation is usually seen between $L$ shells of 2 and 4 at all local times and during varying amounts of magnetic activity; and, well poleward of the plasmapause, a region of intense isotropic pitch angle distributions exists $/ 62,63,64,65 /$. This outer zone of strong pitch angle diffusion was also predicted to be due to cyclotron resonance with protons at higher $L$ values $(L>5)$ where the magnetic field intensity has decreased sufficiently to again produce instability $/ 66 /$.

ICW's, which may be associated with this outer zone of proton precipitation, have been observed. Statistical studies of the occurrence of ICW's at geosynchronous orbit have been performed on GEOS 2 data from a four month period (AugustNovember 1978) and on ATS-6 data over a four month interval (June - October 1974) with surprisingly similar results $167.68,69 \%$. In these studies, the maximum occurrence of left-hand polarized waves at geosynchronous orbit occurred near dusk (Figure 9a), in association with the comparatively higher plasma densities in the dusk bulge region of the plasmasphere. The highest densities in the dusk bulge region $\pi 0$ / were shown statistically to occur at the same magnetic local time (Figure $9 \mathrm{~b}$ ) as the maximum occurrence of ICW's in the above studies. These ICW occurrences were associated with increases in the cold $\mathrm{He}^{+}$ abundance and anisotropic pitch angle distributions of ions having energies $>20 \mathrm{KeV}$ (cf. Korth et al. /67/). These results directly associate anisotropic ring current distributions with the presence of ICW's in the dusk bulge region. The relationship between magnetic activity and the characteristics of ICW's observed by ATS- 6 has been explored $71 \%$. ICW's associated with substorms appear in the frequency range below f $\mathrm{He}^{+}$in the aftemoon sector and are accompanied by a decrease in the magnetic field strength. This decrease is assumed to be due to the injection of energetic, anisotropic ring current particles. ICW's on the dayside occur in the frequency range above fHet in association with a magnetic field compression which is assumed to enhance the anisotropy of energetic protons as a result of betatron acceleration Thus, it appears that ICW's generated in the dusk bulge region provide a mechanism for ring current proton loss and may be associated with the region of strong proton pitch angle diffusion statistically observed to occur on these $L$ shells.

Although observations indicate that ICW's are present in the dusk bulge region, the confirmation of the theoretically-predicted importance of ICW's in the higher-density plasmasphere has not been forthcoming. Several possibilities (among others) exist to explain the discrepancy between theory and observations in this region. Cornwall et al. $/ 60 /$ pointed out that if the Coulomb collision frequency and ICW growth rate become comparable, wave growth will be prohibited. The authors estimate the Coulomb collision frequency to be $10^{-1} \mathrm{~s}^{-1}$ for plasmaspheric densities of $10^{3} \mathrm{~cm}^{-3}$ and $10^{-2} \mathrm{~s}^{-1}$ for plasmaspheric densities of $10^{2} \mathrm{~cm}^{3}$. Revised ICW growth rates in the presence of reasonable amounts of heavy ions are $5 \times 10^{-2}$ to $7 \times 10^{-2} \mathrm{~s}^{-1} / 61 \%$. Therefore, for densities higher than the several hundred per cc typical of the dusk bulge region, Coulomb collisions may effectively prevent ICW growth. The possibility also exists that these waves are present in the high-density plasmasphere but at such low frequencies that they are difficult to measure by spacecraft that have traversed this region. The theoretical results of Kozyra et al. /61/ indicate that wave frequencies may be shifted below $1 \mathrm{~Hz}$ in the presence of observed amounts of heavy ions in the thermal and energetic plasmas in the outer plasmasphere.

Another development in the area of wave particle interactions has to do with the concept of limiting integral flux developed by Kennel and Petschek $/ 72 /$ which assumes an equilibrium exists between wave growth and particle fluxes. Increased ring current and radiation belt particle fluxes result in increased wave growth and ultimately in increased ion precipitation due to pitch angle diffusion into the loss cone. This process maintains a limiting particle flux distribution. Schulz and Davidson $/ 73 /$ have generalized the concept of limiting integral flux above a certain energy threshold developed by Kennel and Petschek $72 /$ to provide a limit of the differential flux with energy above this threshold. Davidson et al. $\pi 4$ / have so far applied this formulation only to ring current electron spectra with interesting results. 


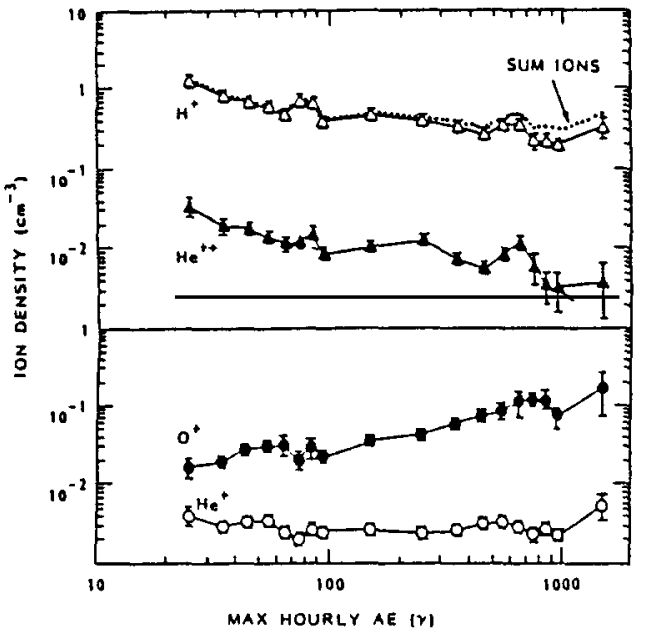

After $/ 52 /$.

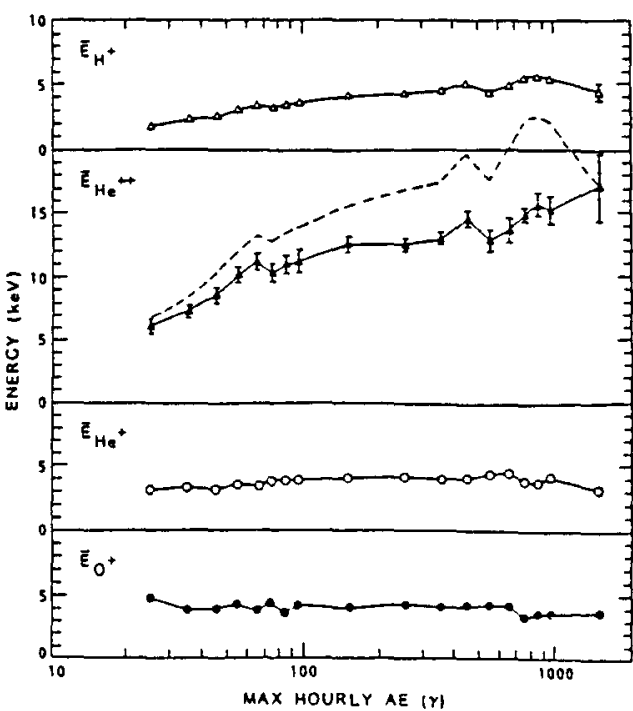

Figure 8. Results of a statistical study of ISEE-1 ion mass spectrometer data in 1978 and 1979 in the energy range $0.1 \mathrm{kev} / \mathrm{e}-16$ $\mathrm{kev} / \mathrm{e}$. Panel (a) gives average absolute ion densities in the plasmasheet and panel (b) average plasmasheet ion energies as a function of AE. The dashed line in panel (b) is 4 times the He+ energy.
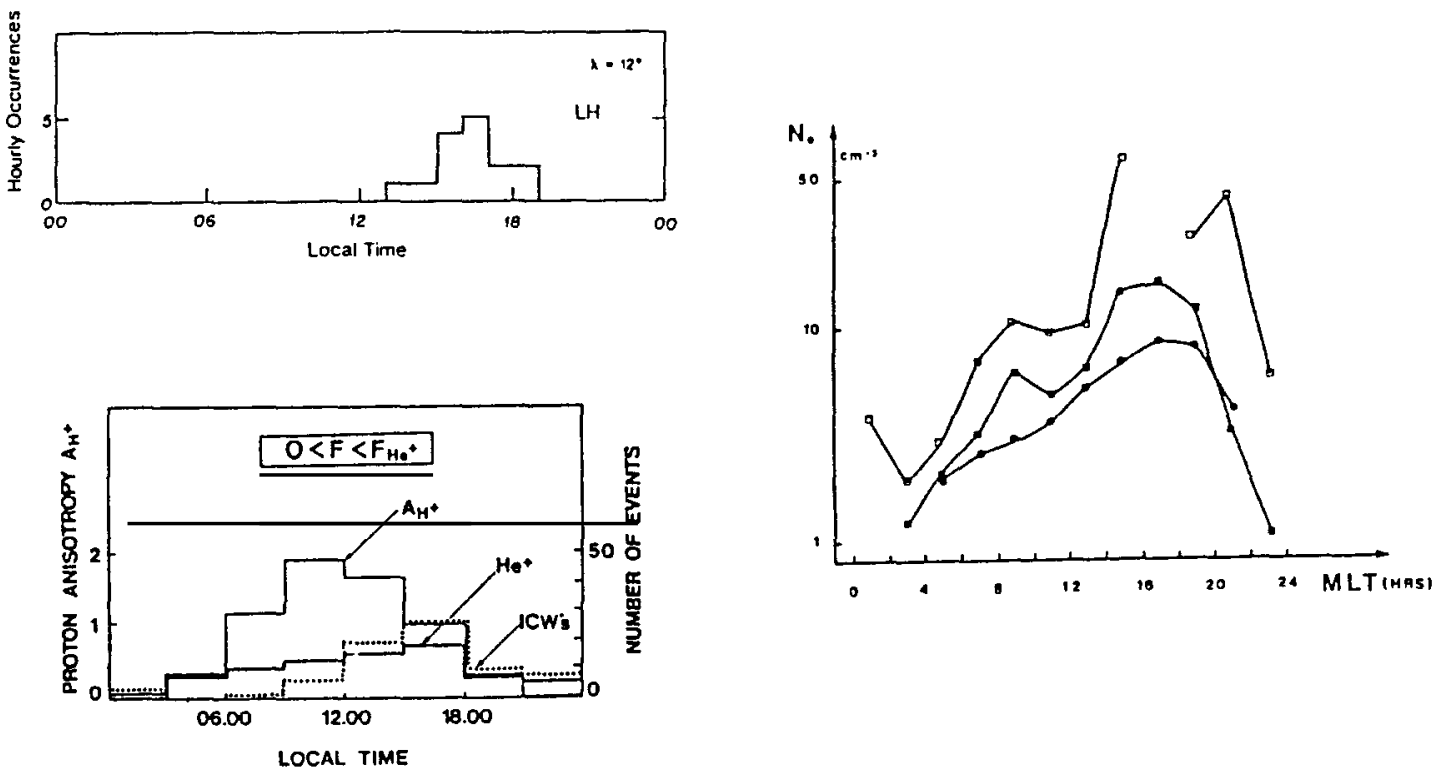

Fig. 9. (a) Local time distribution of left-hand polarized waves from four months (June 19 - October 17, 1974) of ATS 6 observations (upper panel, after 79 ) and from four months (August - November 1978) of GEOS 2 data (lower panel, after 180/. Also in the lower panel are displayed the energetic (45-59 kev) proton anisotropy and the occurrence of $\mathrm{He}^{+}$flux events (He+ fluxes exceeding a certain threshhold). In both cases the occurrence frequency of left-hand, polarized waves peaks near 16 hours local time associated with the dusk bulge region.

(b) Median $\mathrm{N}_{e}$ values versus magnetic local time for $\mathrm{L}=5-6$ (open squares), $\mathrm{L}=6-7$ (filled squares and $\mathrm{L}=7-8$ (filled circles), clearly showing the dusk bulge region which peaks near 16 hours magnetic local time. (after $70 /$ ).

\section{Coulomb Collisions}

Coulomb collisions between ring current protons and thermal electrons within the outer plasmasphere were first proposed by Cole $\pi 5 /$ as the energy source to power stable auroral red (SAR) and conversely, act as a sink for ring current energy. The role of Coulomb collisions between ring current ions and thermal elections in the formation of SAR arcs was evaluated $76 /$ using observations of thermal and energetic ion populations by DE-1 in the outer plasmasphere and nearly simultaneous measurements of enhanced electron temperatures by DE-2 within the SAR arc at F region heights during four SAR arcs in 1981 . Figure 10 displays observations of energetic and thermal plasmas, simultaneously observed F-region electron temperarures, and calculated column-integrated electron heating rates for one modelled SAR arc occurrence. The authors found that (1) sufficient energy was transferred in this manner to support the enhanced (SAR arc) F region election temperatures measured on these field lines, (2) the latitudinal variation of the heating rate was consistent with the observed variation of the election temperature across the SAR arc. and $(3)$ in all cases, ring current $\mathrm{O}^{+}$was the major source of energy for the SAR arcs. All observations were made during storm recovery phases. Thus, Coulomb collisions play a role in the decay of $10-100 \mathrm{kev} \mathrm{RC} \mathrm{\textrm {O } ^ { + }}$ during the recovery phase. 


\section{OCTOBER 1981 SAR ARC}
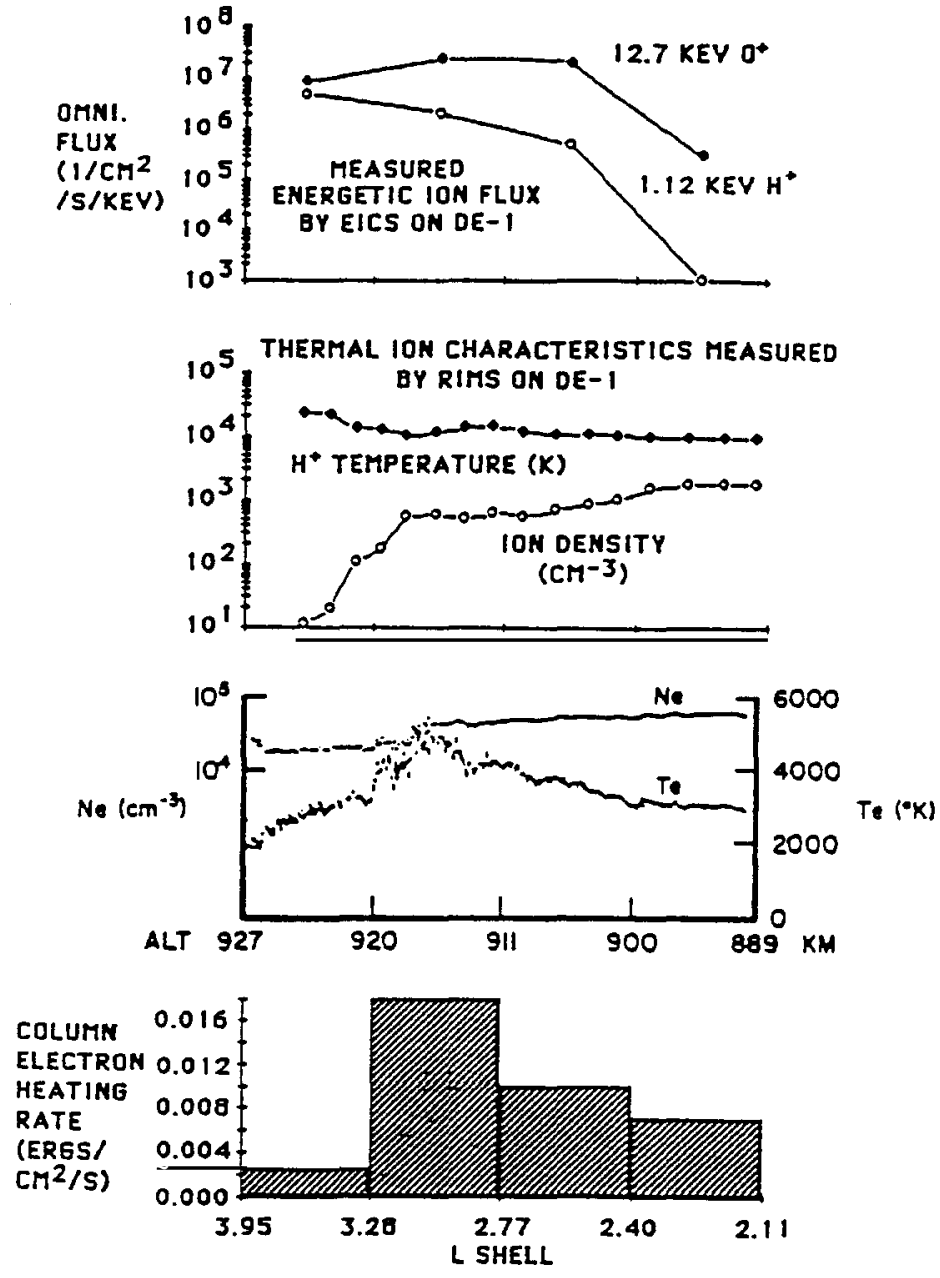

Fig. 10. Summary of energetic and thermal plasma characteristics and calculated column electron heating rates for the SAR arc observed on October 23, 1981. The panels in order from top to botiom display: (1) energetic ion flux at selected energies measured by $D E-1$ in the near-equatorial plasmasphere, (2) thermal ion density and $\mathrm{H}^{+}$temperature measured by $\mathrm{DE}-1$ in the near-equatorial plasmasphere, (3) electron density and temperature measured nearly simultaneously by DE-2 in the $F$ region and (4) calculated column electron heating rate due to Coulomb collisions between the energetic ions and thermal electrons. (after त6).

Coulomb Decay Time

Ring Current $\mathrm{H}+$ and Thermal Electrons

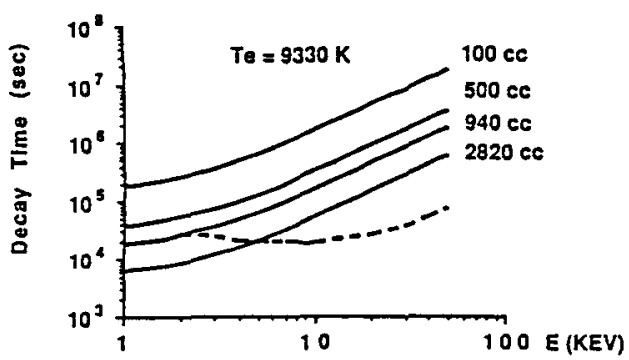

Coulomb Decay Time

Ring Current O+ and Thermal Electrons

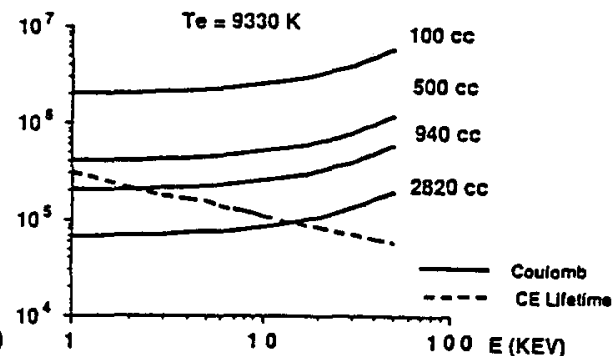

Fig. 11. Coulomb decay times (solid lines) versus energetic ion energy for an energetic $\mathrm{H}^{+}$and $\mathrm{O}^{+}$test particle colliding with thermal electron distributions at $9330 \mathrm{~K}$ for selected thermal electron densities calculated using the theoretical formulation of $/ 78$. Plotted on the same axes are charge exchange lifetimes of $\mathrm{H}^{+}$and $\mathrm{O}^{+}$ions at $\mathrm{L}=3.5$ (From $\left./ 77\right)$.

Finally, Coulomb collisions may play a major role in the decay of the low energy portion of the ring current within the plasmasphere. Figure 11 displays ring current charge-exchange lifetimes at $\mathrm{L}=3.5 \mathrm{from}$ Smith et al. $/ 77 /$ and Coulomb decay times $/ 78 /$ for a range of reasonable plasmaspheric densities. For protons with energies below a few keV and $\mathrm{O}^{+}$at energies below $20 \mathrm{keV}$, Coulomb decay lifetimes are comparable to or shorter than charge exchange lifetimes. 


\section{SUMMARY}

The cleft ion fountain has been identified as a prodigious source of upflowing suprathermal ionospheric plasma. Modeling efforts have traced the path of these ions from the polar ionosphere along trajectories where the ions are energized to keV energies and deposited in the near earth plasma sheet. Mass and energy dispersion of these ions accounts in a natural way for the observed variation in heavy ion content of the plasma sheet. Observations of ion composition in the plasma sheet by the AMPTE and ISEE spacecraft establish that ionospheric ions dominate in the near earth plasma sheet but solar wind ions become significant tailward. The heavy ion content of the plasma sheet increases with both solar cycle and magnetic activity. Direct injection of ionospheric ions into the ring current has been observed in the outer plasmasphere. Several mechanisms for the direct injection of ions from the plasmasphere and ionosphere into the ring current have appeared. Estimation of ionospheric source strengths and residence times have led to an estimate of the magnetospheric densities that would result solely from an ionospheric outflow populating the

magnetosphere. Estimated densities were quite reasonable even without inclusion of a solar wind source of ions. Ring current ions decay primarily via charge exchange with the hydrogen geocorona, however, the roles of pitch angle diffusion and Coulomb collisions in this decay process are being clarified.

Modeling and observations of ENA by the ISEEI spacecraft has led to a re-affimation of the dominant role of charge exchange in ring current decay. Ion cyclotron waves contribute to ring current decay in the dusk bulge region. The role of low frequency. $(<1 \mathrm{~Hz})$ ion cyclotron waves in the plasmasphere is still unclear. Other wave modes may be responsible for the pitch angle diffusion and subsequent loss of ring current ions. Coulomb collisional energy losses from ring current $\mathrm{O}^{+}$to thermal electrons are sufficient to power SAR arcs and represent an energy sink for ring current $\mathrm{O}^{+}$within the plasmasphere. Coulomb collisions may be important for decay of low energy $(<10 \mathrm{KeV})$ ring current ions in the plasmasphere.

\section{REFERENCES}

1. D.J. Williams, The earth's ring current: causes, generation and decay, Space Science Reviews, 34, 223 (1983)

2. D.J. Williams, Space Science Reviews, 42,375 (1985)

3. D.J. Williams, The earth's ring current: Present situation and future thrusts, Phvsica Scriota, T18, 140 (1987a)

4. D.J. Williams, Ring current and radiation belts, Rev, of Geophys, 25, 570 (1987b)

5. L. R. Lyons and D. J. Williams, Quantitative Aspects of Magnetospheric Physics, D. Reidel, Dordrecht, 1984.

6. Spjeldvik, W. N. and P. L. Rothwell, The radiation belts, in: Handbook of Geophysics and the Space Environment, Chapter 5 , Scientific Editor, A. S. Jursa, Air Force Geophysics Laboratory, USAF, 1985.

7. M. Lockwood, J. H. Waite, Jr., T. E. Moore, J. F. E. Johnson, and C. R. Chappell, L Geophys Res, 90,4099 (1985a)

8. M. Lockwood et al., LGeophys. Res., 90, 9736 (1985b)

9. M. Lockwood, T. E. Moore, J. H. Waite, Jr., C. R. Chappell, J. L. Horwitz, and R A. Heelis, Nature, 316, 612 (1985c)

10. J.H. Waite, Jr., et al., L. Geophys Res., 90, 1619 (1985)

11. J.H. Waite, Jr., et al., Geophys Monogr. Ser., Vol 38, edited by T. Chang, p.61, AGU, Washington, D.C., 1986.

12. T.E. Moore, C. R. Chappell, M. Lockwood, and J. H. Waite, Jr., L. Geophys. Res., 90, 1611 (1985)

13. T.E. Moore, M. Lockwood, M.O. Chandler, J. H. Waite, Jr., A. Persoon and M. Suguira, L. Geophys. Res. 91, 7019 (1986)

14. J.L. Horwiz, Features of ion trajectories in the polar magnetosphere, Geophys, Res. Lett, 11, 1111 (1984)

15. J.L. Horwitz and M. Lockwood, The cleft ion fountain: A two-dimensional kinetic model, L.Geophys. Res, 90,9749 (1985)

16. J.L. Horwitz, J. H, Waite, Jr., and T. E. Moore, Geophys Res. Letl., 12, 757 (1985)

17. J.L. Horwitz et al, Geophys. Monogr. Ser., vol. 38, edited by T. Chang, p.56, AGU, Washington, D.C. , 1986.

18. C. Gurgiolo and J. L. Burch, Composition of the polar wind - Not just $\mathrm{H}^{+}$and $\mathrm{He}^{+}$, Geophys. Res, Lett., 12, 69 (1985)

19. J.L. Green and J. H. Waite, Jr., Geophys. Res. Lett, 12, 149 (1985)

20. T.I. Gombosi and T. L. Killeen, LGeophys. Res, 92, 4725 (1987)

21. M. Lockwood, M. F. Smith, C. J. Farnugia, and G. L. Siscoe, L Geophys, Res. 93,5641 (1988)

22. M. Lockwood et al., LGeophys. Res. 90, 9736 (1985b)

23. A.W. Yau, E. G.Shelley, W. K. Peterson, and L. Lenchyshyn, L.Geophus. Res., 90,8417 (1985)

24. J.L. Horwitz, Core Plasma in the Magnetosphere, Rev, of Geophys., 25, 579 (1987)

25. J.B. Cladis, Geophys. Bes. Lelt., 13, 893-896 (1986)

26. J.L. Horwiz, The ionosphere as a source of magnetospheric ions, Rev. Geophys, and Space Phys., 20, 929 (1982)

27. D.J. Williams, Ring current composition and sources: An update, Planet. Space Sci. 29, 11, 1195 (1981)

28. D. T. Young. Near-equatorial magnetospheric particles from $\sim$ lev to $-1 \mathrm{Mev}$, Rev, of Geophys and Space Phys, 21,402 (1983)

29. J.M. Bosqued, J. A. Sauvaud, D. Delcourt, and R. A. Kovrazhkin, L. Geophys. Res, 91, 7006 (1986)

30. R.G. Johnson, Energetic ion composition in the earth's magnetosphere, Rev. Geophys, 17, 696 (1979)

31. P. F. Mizera, et al. The aurora inferred from S3-3 particles and fields, L. Geophys. Res., 86.2329 (1981)

32. A.G. Ghielmetti, R. D. Sharp, E. G. Shelley, and R. G. Johnson, L. Geophys. Res, 84, 5781 (1979)

33. S.M. Kaye, E. G. Shelley, R. D. Sharp, and R. G. Johnson, Ion composition of zipper events, L_Geophys, Res, 86, 3383 (1981)

34. J.M. Bosqued, Ion precipitation into the ionosphere during geomagnetic storms, Adv. Space Res., 5,179 (1985)

35. N.V. Jorjio et al., Adv. Space Res, 5, 141 (1985) 
36. J. D. Menietti, et al.. J. Geophys. Res, 90, 1653 (1985)

37. P.T. Newell and C.-I. Meng, LGeophy. Res, 91,11133 (1986)

38. L. Gomberoff and P. Vega, L. Geophys. Res, 92,7728 (1987)

39. L. Gomberoff and M. Molina, L. Geophys. Res, 90, 1776 (1985)

40. R. Gendrin, Space Sci. Reviews, 34, 271 (1983a)

41. R. Gendrin, in High-Latitude Space Plasma Physics, edited by B. Hultqvist and T. Hagfors, 415. Plenum, New York, $1983 b$

42. A. Korth, G. Kremser, S. Perraut, and A. Roux, Planet. Space Sci., 32, 1393 (1984)

43. B. Inhester, U. Wedeken, A. Korth, S. Perraut, and M. Stokholm, L. Geophys. Res, 55, 134 (1984)

44. B. J. Fraser, J. C. Samson, R. L. McPherron, and C. T. Russell, Adv Space Res, 6, 223 (1986)

45. D.T. Young, et al., L. Geophys. Res, 86, 6755 (1981)

46. H.L. Collin, R. D. Sharp, and E. G. Shelley, L Geophys. Res, 89, 2185 (1984)

47. C. R. Chappell, T. E. Moore, and J. H. Waite, Jr., L. Geophys. Res., 92, 5896 (1987)

48. G. Gloeckler and D. C. Hamilton, AMPTE ion composition results. Physica Scripts, T18, 73 (1987)

49. B. Klecker, E. Mobius, D. Hovestadt, M. Scholer, G. Gloeckler, and F. M. Ipavich, Geonhys, Res. Lett, 13, 632 (1986)

50. W.N. Spjeldvik and T. A. Fritz, L. Geophys. Res, 83, 1583 (1978)

51. G. Kremser, W. Studemann, B. Wilken, G. Gloeckler, D. C. Hamilton, F. M. Ipavich, L, Geophys Res, 92,4459 (1987)

52. W. Lennartsson and E. G. Shelley, Survey of 0.1 to $16 \mathrm{kev} / \mathrm{e}$ plasma sheet ion composition, LGeophys. Res, 91,3061 (1986)

53. W. K. Peterson, R. D. Sharp, E. G. Shelley, and R. G. Johnson, L. Geophys, Res, 86, 761 (1981)

54. R. D. Sharp, W. Lennartsson, W. K. Peterson, and E. G. Shelley, J. Geophys. Res. 87, 10420 (1982)

55. W. Lennartsson and R. D. Sharp, Adv. Space Res., 4, 411 (1985)

56. A. W. Yau, B. A. Whalen, W. K. Peterson and E. G. Shelley, Distribution of upflowing ionospheric ions at the high-altitude polar cap and auroral ionosphere, L. Geophys. Res, 89, 5507 (1984)

57. D. T. Young, H. Balsiger, and J. Geiss, J. Geophys. Res., 87, 9077 (1982)

58. E. C. Roelof, D. G. Mitchell, and D. J. Williams, L. Geophys. Res., 90, 10991 (1985)

59. W. Studemann et al., Geophys. Res, Lett, 14, 455-458, 1986.

60. J. M. Cornwall, F. V. Coroniti, and R. M. Thome, Turbulent loss of ring current protons, L. Geophys, Res, 75, 4699, 1970

61. J. U. Kozyra, T. E. Cravens, A. F. Nagy, E. G. Fontheim, R. S. B. Ong, L. Geophys. Res., 89, $2217(1984)$

62. D. J. Williams and L. R. Lyons, J. Geophys. Res. 79, 4195 (1974a)

63. D. J. Williams and L. R. Lyons, L. Geophys. Res, 79,4791 (1974b)

64. J. A. Lundblad, and F. Soraas, Planet. Space Sci, 26, 245 (1978)

65. F. Soraas, J. A. Lundblad, and B. Hultqvist, Planel. Space Sci, 25, 757 (1977)

66. J. M. Cornwall, F. V. Coroniti, and R. M. Thorne, LGeophys. Res, 76, 4428 (1971)

67. A. Korth, G. Kremser, S. Perraut, and A. Roux, Planet. Space Sci, 32, 1393 (1984)

68. B.J. Fraser, J. C. Samson, R. L. McPherron, and C. T. Russell, Adv, Space Res, 6, 223 (1986)

69. BJ. Fraser, Pc 1-2 observation of heavy ion effects by synchronous satellite ATS-6. Planet. Space Sci, 30, 1229 (1982)

70. P.M.E. Decreau, C. Beghin and M. Parrot, L. Geophys, Res., 87, 695, (1982)

71. J. Ishida, S. Kokubun, and R. L. McPherron, L Geophys, Res., 92, 143 (1987)

72. C. F. Kennel and H. E. Petschek, Limit on stably trapped particle fluxes, L. Geophys. Res.. 71, 1 (1966)

73. M. Schulz and G. T. Davidson, Limiting energy spectrum of a saturated radiation belt, L. Geophys. Res. 93,59 (1988)

74. G. T. Davidson, P. C. Filbert, R. W. Nightingale, W. L. Imhof, J. B. Reagan, and E. C. Whipple, L Geophys. Res, 93, 77 (1988)

75. K. D. Cole, Stable auroral red arcs, sinks for energy of $D_{S t}$ main phase, L. Geophys. Res, 70, 1689 (1965)

76. J. U. Kozyra, E. G. Shelley, R. H. Comfort, L. H. Brace, T. E. Cravens, and A. F. Nagy, L. Geophys, Res, 92, 7487 (1987)

77. R. H. Smith, N. K. Bewtra, and R. A. Hoffman, J. Geophys. Res., 86, 3470 (1981)

78. L. Spitzer, Jr., Physics of Fully Ionized Gases, Interscience, New York, 1962.

79. B.I. Fraser, and R. L. McPherron, L. Geophys, Res., 87, 4560, 1982.

80. A. Roux, S. Perraut, J.L. Rauch, C. deVilledary, G. Kremser, A. Korth, D.T. Young, L. Geophys, Res. 87, 8174, 1982. 